\title{
Sosialisasi Penataan Rumah yang Rapi Menggunakan Fischer di Kecamatan Sematang Borang
}

\author{
Mahmud Basuki' ${ }^{1}$, Selvia Aprilyanti*2, Winny Andalia ${ }^{3}$, Hermanto MZ $^{4}$, Azhari ${ }^{5}$ \\ 1,2,3,4,5 Program Studi Teknik Industri, Fakultas Teknik, Universitas Tridinanti Palembang \\ *e-mail: mahmudbasuki@univ-tridinanti.ac.id¹, selvia1704@univ-tridinanti.ac.id²
}

\begin{abstract}
Implementation of community service (PKM) carried out in Sukamulya Village, Sematang Borang Subdistrict, Palembang City was motivated by a lack of knowledge and understanding of the community regarding physical aids in residential structuring. Fischer or viser is a tool for connecting screws made by plastic material that is commonly used for household installation purposes such as installing shelves, curtains, TV briquettes and so forth. The PKM method is carried out through socialization, the practice of installing a physical exam and a survey of material understanding using a questionnaire. The results of the socialization showed 75\% more understanding and knowledge of the people of Sukamulya Village on the installation of fischer in the arrangement of the house to make it more presentable.
\end{abstract}

Keywords: arrangement, house, fischer, socialization

\begin{abstract}
Abstrak
Pelaksanaan pengabdian kepada masyarakat (PKM) yang dilaksanakan di Kelurahan Sukamulya, Kecamatan Sematang Borang, Kota Palembang dilatarbelakangi oleh kurangnya pengetahuan dan pemahaman masyarakat terhadap alat bantu fischer dalam penataan rumah tinggal. Fischer atau viser adalah alat bantu untuk mengaitkan sekrup yang terbuat dari bahan plastik yang biasa digunakan untuk keperluan instalasi rumah tangga seperti memasang rak, gorden, briket TV, dan lain sebagainya. Metode PKM dilaksanakan melalui sosialisasi, praktik pemasangan fischer dan survey pemahaman materi menggunakan kuesioner. Hasil sosialisasi menunjukkan 75\% lebih adanya pemahaman dan pengetahuan masyarakat Kelurahan Sukamulya terhadap pemasangan fischer dalam penataan rumah agar lebih rapi.
\end{abstract}

Kata kunci: Fischer, sosialisasi, rumah, rapi

\section{PENDAHULUAN}

Mayoritas masyarakat Indonesia masih memiliki hunian atau rumah dengan ukuran yang minimalis dan berukuran kecil. Begitu juga dengan ukuran rumah masyarakat di Kelurahan Sukamulya Kecamatan Sematang Borang Kota Palembang. Dengan ukuran rumah yang kecil, seringkali masyarakat mengalami kerumitan dalam mendekorasi dan menata perabotan rumah tangga agar terlihat nyaman dan menarik. Dimana, dekorasi merupakan suatu aktivitas penambahan dalam suatu rumah untuk mendapatkan nilai estetika (Veronica, 2018) yang mengacu pada keindahan audiovisual maupun imajinatif (Mastuti, 2019) sehingga penghuni akan merasa nyaman dan betah (Werdiningsih, Indrosaptono, \& Darmawan, 2015). Dekorasi ruang penting untuk diperhatikan karena dapat memberikan citra visual yang baik (Desintha, 2019) karena ruang merupakan tempat manusia untuk melakukan interaksi, kreasi, dan aksi (Chressetianto, 2013)(Rusli, 2011). Dalam mendekorasi tidak harus menggunakan materialmaterial yang baru, untuk mendukung pengurangan limbah, dalam mendekorasi rumah dapat menggunakan material dari bahan bekas atau daur ulang (Tjandra, Ardana, \& Yong, 2017) yang tidak akan mengurangi nilai-nilai estetika keindahan dan kepuasan kenyamanan. Dengan ruang yang baik, akan meningkatkan kepuasan serta kenyamanan bagi penghuni, dimana kepuasan merupakan suatu hal yang dapat memenuhi ekspektasi keinginan, harapan, kebutuhan, serta tidak adanya keluhan (Mujiraharjo \& Basuki, 2019).

Bukanlah hal yang mudah untuk mendekorasi rumah dengan desain ukuran ruangan yang kecil. Banyaknya barang atau perabotan menjadi permasalahan utama dalam penataan rumah. Dinding ruangan adalah space yang dapat dimaksimalkan untuk beragam fungsi dan tujuan. Selain untuk memajang karya seni atau foto, dinding ruangan bisa dimanfaatkan untuk instalasi sebuah 
rak serbaguna yang dapat menyimpan beberapa barang. Biasanya barang-barang yang bobotnya lebih berat serta mempunyai ukuran besar, jika dipasang hanya menggunakan paku saja tentu kekuatannya untuk menahan beban kurang begitu kuat. Apalagi jika dinding tembok menggunakan batako yang banyak digunakan pada masyarakat Kelurahan Sukamulya, Kecamatan Sematang Borang, tentu dalam pemasangan dekorasi rumah atau instalasi lainnya jauh dari kata kokoh dan rapi. Batako merupakan bahan bangunan yang terbuat dari campuran seperti kapur, bahan perekat yang hidrolis, agregat, pasir dan air kemudian dicetak sesuai dengan standar kebutuhan bangunan (Darmono, 2006). Oleh karena itu, diperlukan adanya bantuan peralatan yang bagus untuk mengorganisir segala sesuatu di dalam rumah dan memanfaatkan space yang tersedia agar menjadikan setiap ruangan tampak rapi dan kokoh.

Fischer merupakan salah satu alat penata ruangan dengan jenis sekrup modern sebagai salah satu teknologi bidang konstruksi. Fischer lebih sering digunakan pada dinding yang merupakan beton struktur, namun tetap bisa dipasang pada dinding biasa yang menggunakan bahan batu bata, behel dan sejenisnya. Fischer ini menyerupai seperti jangkar sehingga disebut juga sebagai angkur dinding atau anchor wall. Fischer membuat sekrup atau gantungan menjadi stabil dan tidak mudah bergerak atau goyang. Jika masih bisa bergoyang atau gerak berarti ada masalah dan sebaiknya sekrup diganti atau bahkan fischernya diganti (Builder Indonesia, 2018).

Biasanya masyarakat di Kecamatan Sematang Borang pada umumnya menggunakan paku untuk memasang benda pada dinding rumah. Namun penggunaan paku tidak mampu untuk menyangga benda yang berat seperti lemari kecil atau televisi. Untuk mengatasi permasalahan tersebut maka perlu menggunakan fischer agar dapat menyangga dan menahan benda yang berat yang tergantung pada dinding rumah. Penggunaan alat ini masih belum cukup terkenal dikalangan masyarakat biasa karena kebanyakan alat ini digunakan pada konstruksi bangunan modern. Sehingga masyarakat di Kecamatan Sematang Borang juga belum memiliki pengetahuan dan keterampilan yang baik dalam pengaplikasian fischer terhadap dinding rumah mereka. Oleh karena itu, melalui program pengabdian kepada masyarakat ini dilakukan sosialisasi terhadap masyarakat di Kecamatan Sematang Borang khususnya di Kelurahan Sukamulya mengenai tata cara penggunaan fischer yang tepat dalam penataan rumah. Hal ini dilakukan karena masih kurangnya pengetahuan masyarakat tentang manfaat dan kelebihan fischer dibandingkan penggunaan paku dalam penataan benda pajangan pada dinding rumah.

\section{METODE}

Adapun langkah awal yang dilakukan adalah menyiapkan seperangkat alat dan bahan untuk pemasangan fischer. Tahapan selanjutnya melakukan persiapan pelaksanaan yaitu pemantapan jadwal dengan cara penentuan jadwal bersama mitra setelah usulan kegiatan disetujui untuk dilaksanakan (Rahmah, Emidar, \& Zulfikarni, 2018). Selanjutnya menetapkan tempat dan waktu serta mengirim undangan kepada mitra pengabdian yaitu masyarakat di Kelurahan Sukamulya Kecamatan Sematang Borang. Tempat sosialisasi dilaksanakan di kantor Kelurahan Sukamulya di Jalan Sunarna No.1 RT.1 RW.1 Kecamatan Sematang Borang. Waktu pelaksanaan sosialisasi sesuai dengan jadwal pelaksanaan yang diizinkan oleh lurah yaitu pada tanggal 20 Februari 2020. Jumlah mitra yang mengikuti kegiatan ini adalah sebanyak 20 orang peserta dari masyarakat Kelurahan Sukamulya Kecamatan Sematang Borang.

Metode pelaksanaan kegiatan pengabdian kepada masyarakat berupa kegiatan sosialisasi pemasangan fischer untuk mewujudkan rumah yang rapi dengan metode ceramah dan praktik. Sosialisasi dilakukan selama 1 hari, dan tahapan sosialisasi dilaksanakan dengan urutan kegiatan sebagai berikut:

a. Acara pembukaan kegiatan sosialisasi yang dimulai dengan maksud dan tujuan serta manfaat bagi peserta tentang pelaksanaan sosialisasi penggunaan fischer untuk mewujudkan rumah yang rapi selama kurang lebih 30 menit. 
b. Mempraktikkan tata cara penggunaan fischer pada dinding dan menempatkan benda-benda yang akan dipajang.

c. Menyebarkan kuesioner sebagai indikator pengukur pengetahuan peserta terhadap penggunaan fischer setelah sosialisasi selama kurang lebih 15 menit.

Penilaian nantinya dilakukan terhadap jawaban peserta sosialisasi dalam menjawab kuesioner yang telah diberikan. Bila terjadi peningkatan yang cukup signifikan maka dapat dikatakan kegiatan sosialisasi yang diberikan mendapatkan hasil positif sesuai dengan tujuan dilakukannya program pengabdian kepada masyarakat.

\subsection{Materi}

Materi yang disosialisasikan dibagi atas beberapa tahapan yaitu memberikan penjelasan mengenai manfaat dan kelebihan fischer, harga beli alat dan bahan yang digunakan pada pemasangan fischer dan tata cara pengaplikasian fischer pada dinding.

Adapun materi sosialisasi diawali dengan pengadaan alat dan bahan yang digunakan, hardcopy panduan pemasangan fischer yang dibagikan kepada peserta dan dilakukan praktik langsung tata cara pemasanganfischer pada dinding rumah peserta mitra.

\section{2 Peralatan dan Bahan}

\subsubsection{Alat yang Digunakan}

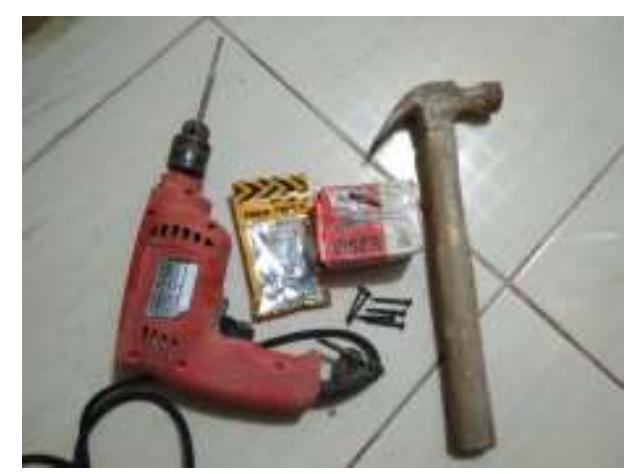

Gambar 1. Alat-alat yang digunakan

a. Bor

Ada beberapa macam bor dengan berbagai merek. Ada bor listrik dan ada juga bor yang menggunakan baterai. Jika melihat fungsinya bor menggunakan baterai lebih simpel dan mudah dibawa kemana-mana tanpa harus ada aliran listrik. Berbeda halnya dengan bor listrik, penggunaannya harus menggunakan aliran listrik, sehingga akan terasa tidak praktis jika bor digunakan untuk memasang atap rangka baja di atas rumah karena kabel yang tersambung ke aliran listrik butuh dikendalikan. Terkait harga beraneka ragam, bor listrik biasanya dihargai dimulai dari Rp. 300.000.

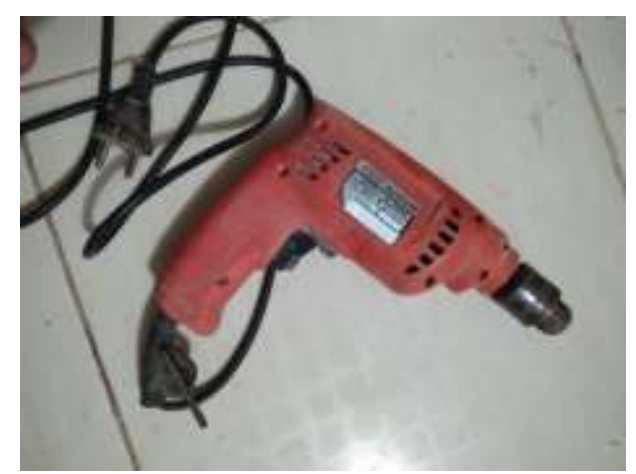

Gambar 2. Bor listrik 
b. Mata bor ukuran $6 \mathrm{~mm}$

Mata bor ini banyak dijual di toko bangunan. Mata bor juga banyak macamnya dengan berbagai merek. Ada mata bor yang khusus untuk keramik, besi, dan beton. Namun percobaan pada artikel ini menggunakan mata bor beton ukutan $6 \mathrm{~mm}$. Untuk harga dimulai dari Rp. 10.000.

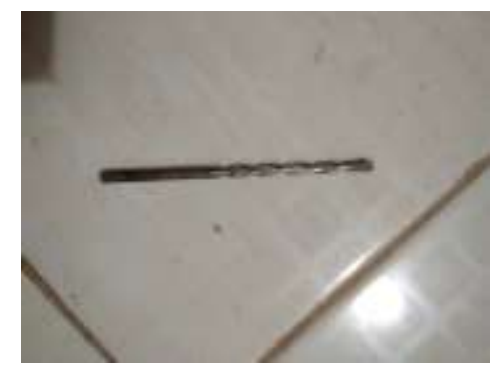

Gambar 3. Mata bor

c. Palu

Palu atau martil juga biasa dijual di toko bangunan. Palu ini digunakan untuk memasukkan fischer pada tembok yang sudah di bor. Untuk harga juga bervariasi dimulai dari Rp. 40.000 .

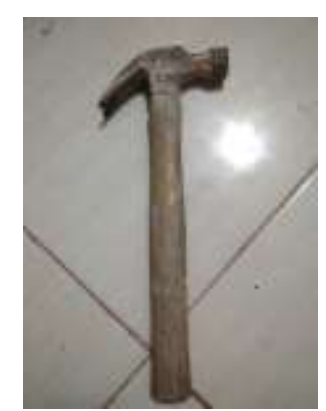

Gambar 4. Palu atau martil

d. Meteran

Meteran banyak dijual di toko bangunan dengan berbagai merk. Meteran digunakan untuk mengukur letak barang yang akan ditempatkan pada tembok supaya presisi dan sesuai dengan yang diharapkan. Harga meteran dimulai dari Rp. 12.000.

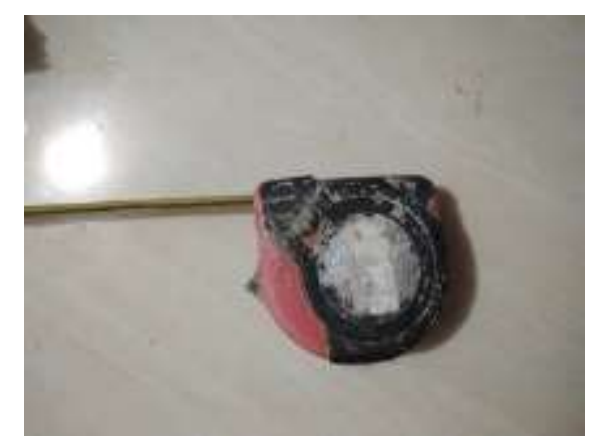

Gambar 5. Meteran

\subsubsection{Bahan yang Digunakan}

a. Fischer S6

Fischer S6 (Viser S6) bisa didapat di toko bangunan. Biasanya satu kotak berisi 100 pcs. Harga satu kotak dimulai Rp. 9.000. 


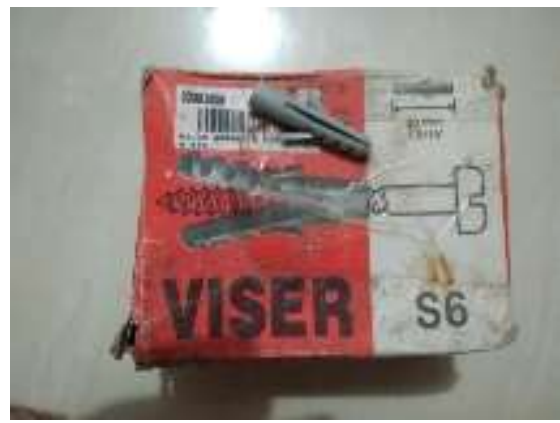

Gambar 6. Viser atau fischer

b. Sekrup gantung $6 \mathrm{~cm}$

Sekrup ini didapat dari supermarket bangunan, harganya cukup murah hanya Rp. 4.000/ 12 pcs.

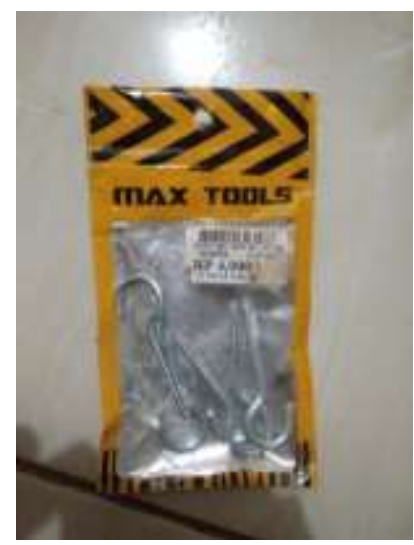

Gambar 7. Sekrup gantung

c. Sekrup diameter $3,5 \mathrm{~mm}$, panjang $25 \mathrm{~mm}-38 \mathrm{~mm}$

Sekrup banyak sekali macamnya, dan harga tentu bervariasi. Ada yang menjual satu kotak, ada yang bijian. Untuk sekrup bijian biasa dihargai Rp. 100 per/biji.

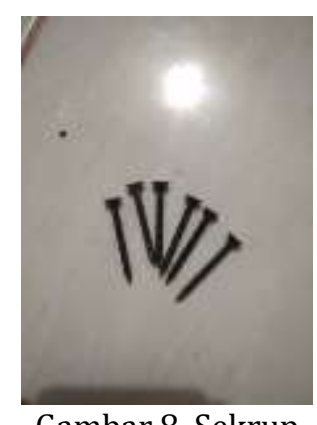

Gambar 8. Sekrup

2.3 Prosedur Pemasangan Fischer

a. Penentuan titik

Dalam menentukan titik, digunakan alat meteran supaya lebih tepat dari segi tinggi maupun jarak ukuran yang akan dipasang. Pemberian titik dapat menggunakan spidol maupun pensil, atau bisa juga menggunakan paku.

b. Pengeboran tembok

Sebelum pengeboran dimulai, pasang terlebih dahulu mata bor ke bor listrik. 

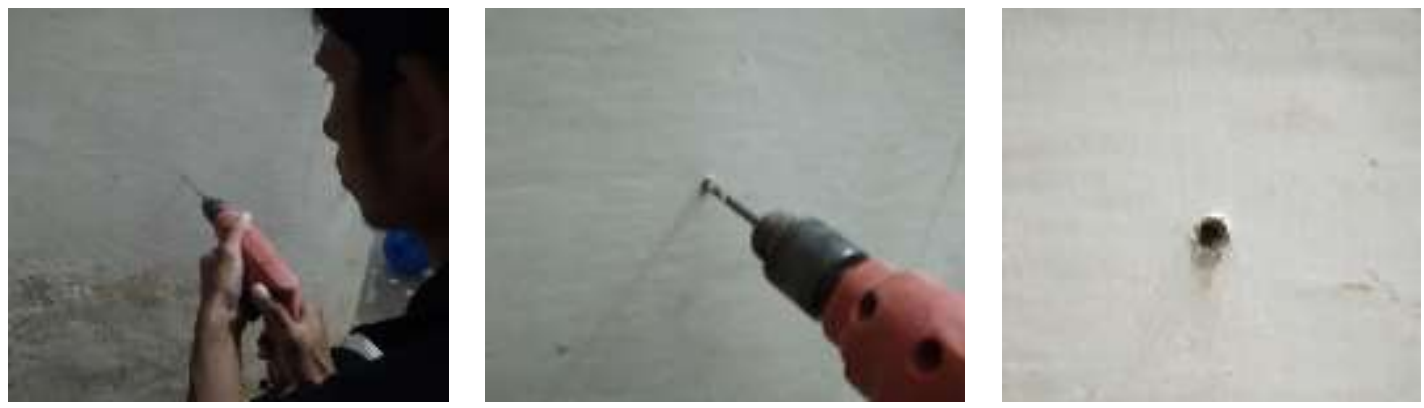

Gambar 9. Proses pengeboran tembok

c. Pemasangan fischer

Proses pemasangan fischer menggunakan alat yaitu palu atau martil untuk memberikan tekanan fischer ke dalam tembok.
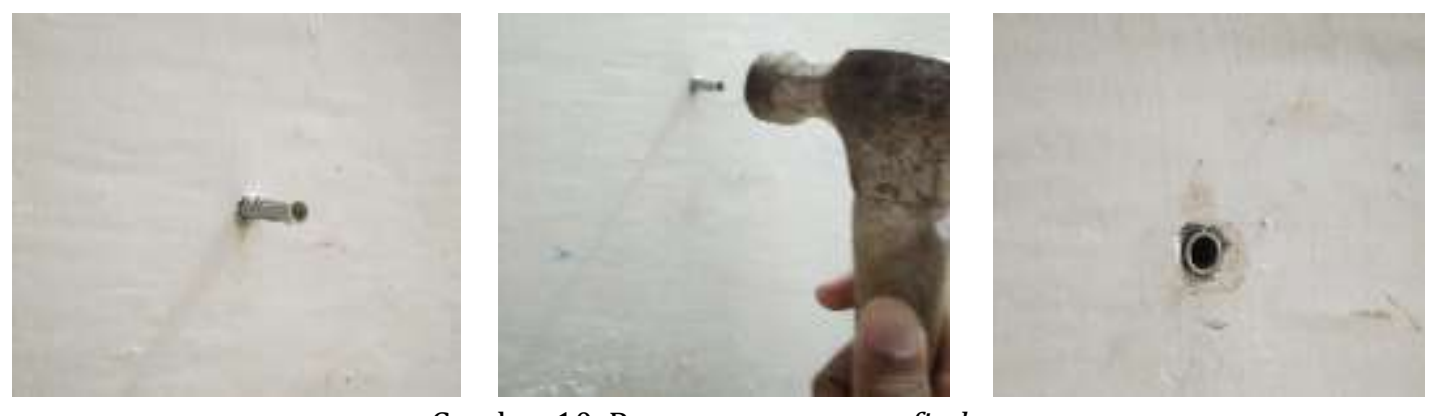

Gambar 10. Proses pemasangan fischer

d. Pemasangan benda yang akan dipasang

Fischer yang terpasang siap untuk diberi sekrup, baik sekrup biasa maupun sekrup gantung sesuai dengan kebutuhannya. Sekrup biasa, sebagai contohnya dalam pemasangan horden, briket tv, dan lain-lain. Sekrup gantung sebagai contoh untuk pemasangan gantungan sapu dan lain-lain.

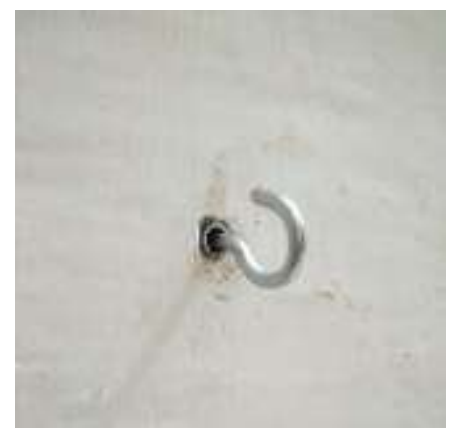

Gambar 11. Hasil percobaan

\subsection{Hasil Pemasangan Fischer}
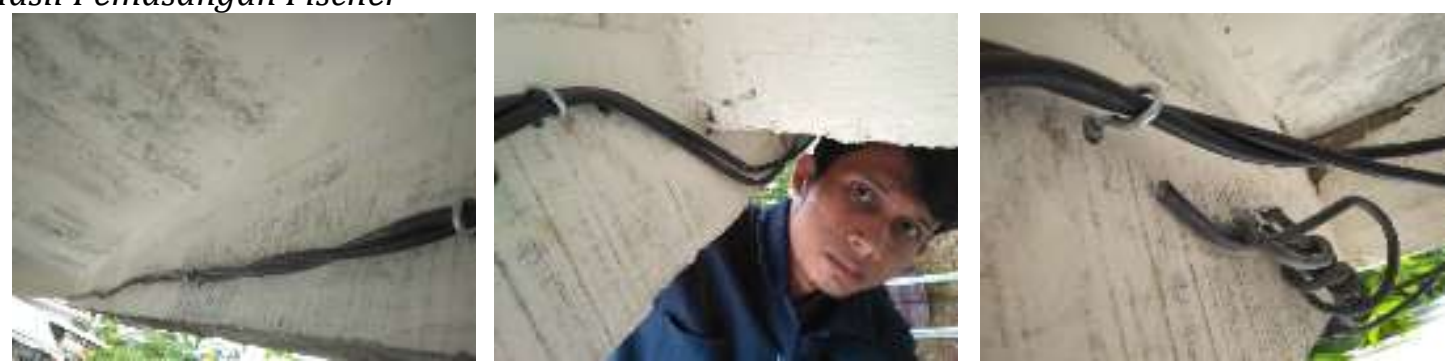

Gambar 12. Kabel yang rapi 

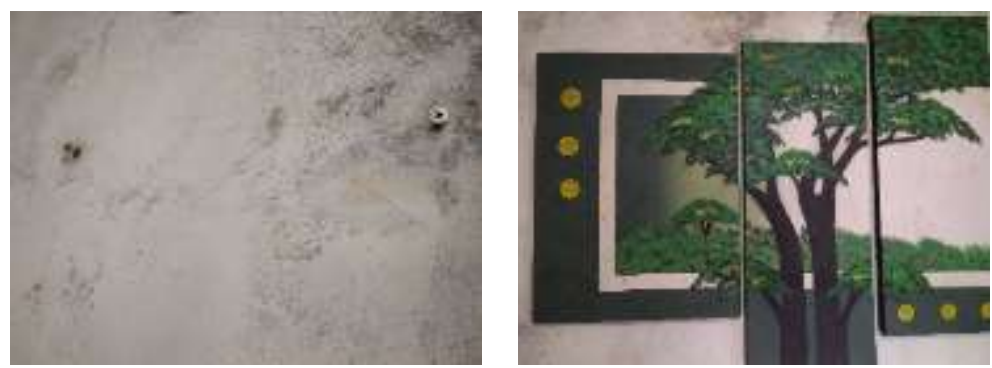

Gambar 13. Pemasangan lukisan
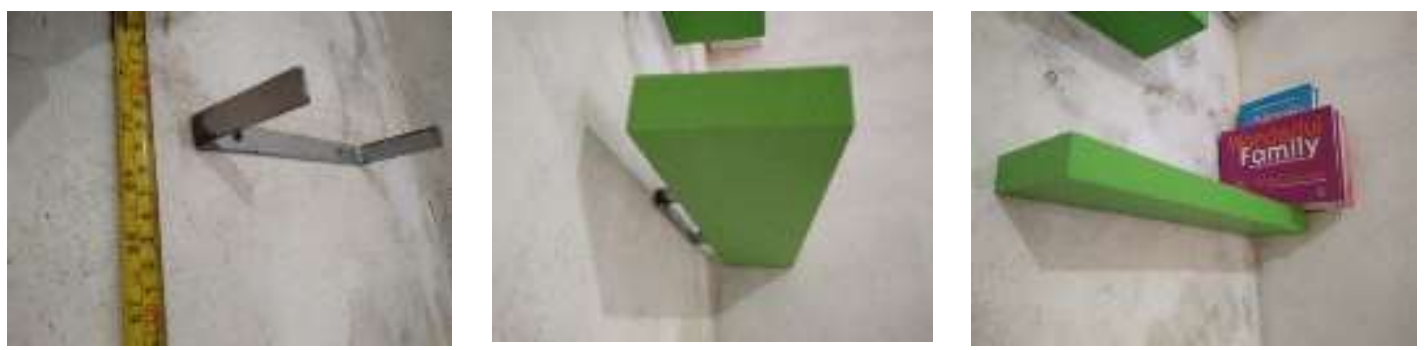

Gambar 14. Pemasangan rak

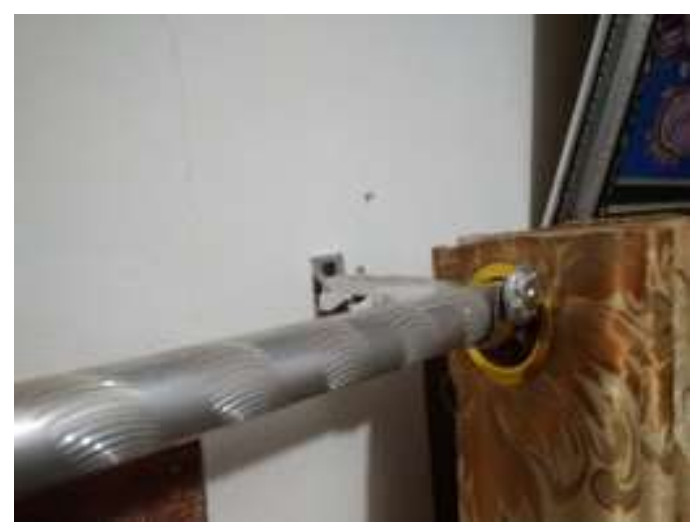

Gambar 15. Pemasangan horden

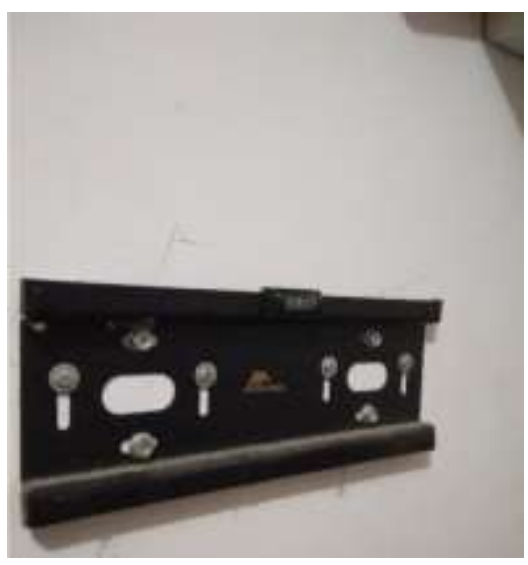

Gambar 16. Pemasangan briket TV

\section{HASIL DAN PEMBAHASAN}

Hasil yang dicapai dalam pelaksanaan kegiatan sosialisasi penggunaan fischer ini adalah mengetahui tingkat antusias peserta dalam mengikuti sosialisasi, peran serta aktif peserta dalam kegiatan, serta bertambahnya pengetahuan peserta tentang manfaat dan kelebihan penggunaan 
fischer dibandingkan paku. Berdasarkan kegiatan sosialisasi yang telah dilaksanakan tersebut maka diperoleh hasil sebagai berikut:

\subsection{Data Diri Responden}

Berdasarkan tingkat umur responden diperoleh 32\% responden memiliki usia 40 tahun ke atas. Selebihnya sebesar 68\% responden memiliki usia diantara 15-39 tahun. Dari hasil tersebut seperti pada gambar 17 , diketahui tingkatan umur responden yang hadir dapat diketahui bahwa 68\% responden adalah usia produktif artinya memiliki potensi kemampuan untuk menerapkan pemasangan fischer di lingkungan rumah.

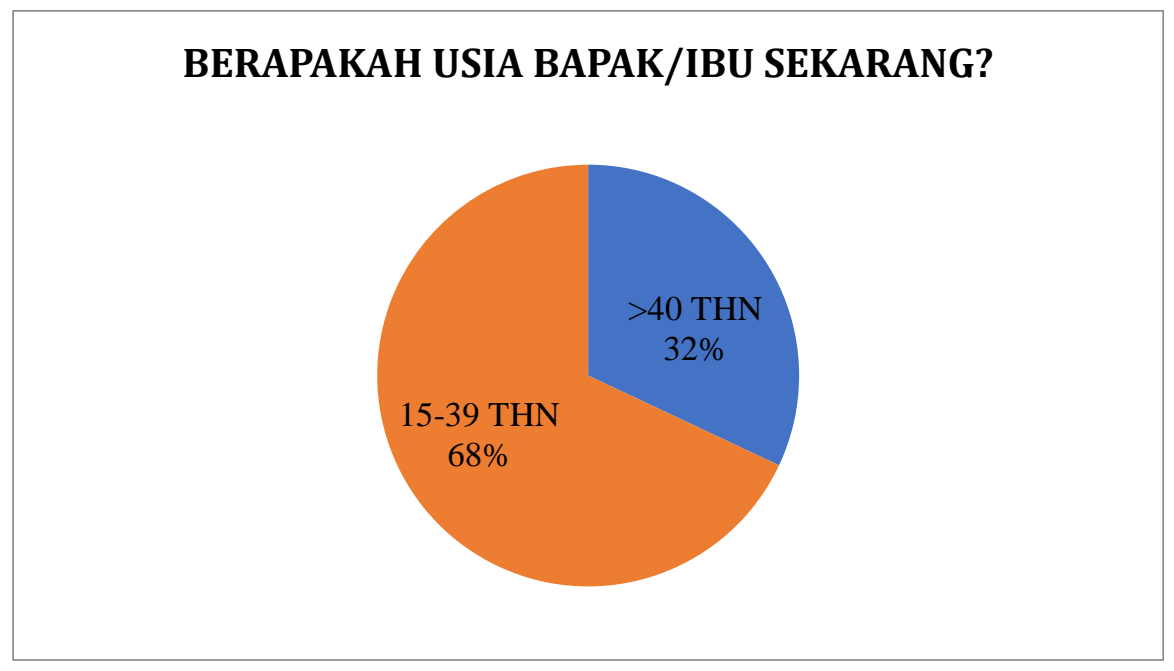

Gambar 17. Tingkatan umur responden

Sekolah merupakan tingkat pendidikan yang ditempuh oleh masyarakat baik secara formal maupun non formal (Desriyeni, Rahmah, \& Marlini, 2018). Tinggi rendahnya tingkat pendidikan akan mempengaruhi tingkat pemahaman masyarakat terhadap materi yang disosialisasikan. Berdasarkan tingkatan pendidikan peserta yang hadir seperti pada gambar 18, dapat diketahui bahwa sebesar 13\% peserta memiliki pendidikan terakhir tingkat SD dan 55\% memiliki pendidikan terakhir SLTP/Sederajat atau SLTA/sederajat. Selebihnya sebesar 32\% memiliki tingkat pendidikan akademi atau perguruan tinggi. Oleh karena itu diperoleh bahwa persentase terbanyak adalah tingkat SLTP dan SLTA yang diharapkan memiliki potensi kemampuan pemahaman yang tinggi untuk menerapkan pemasangan fischer di lingkungan rumah.

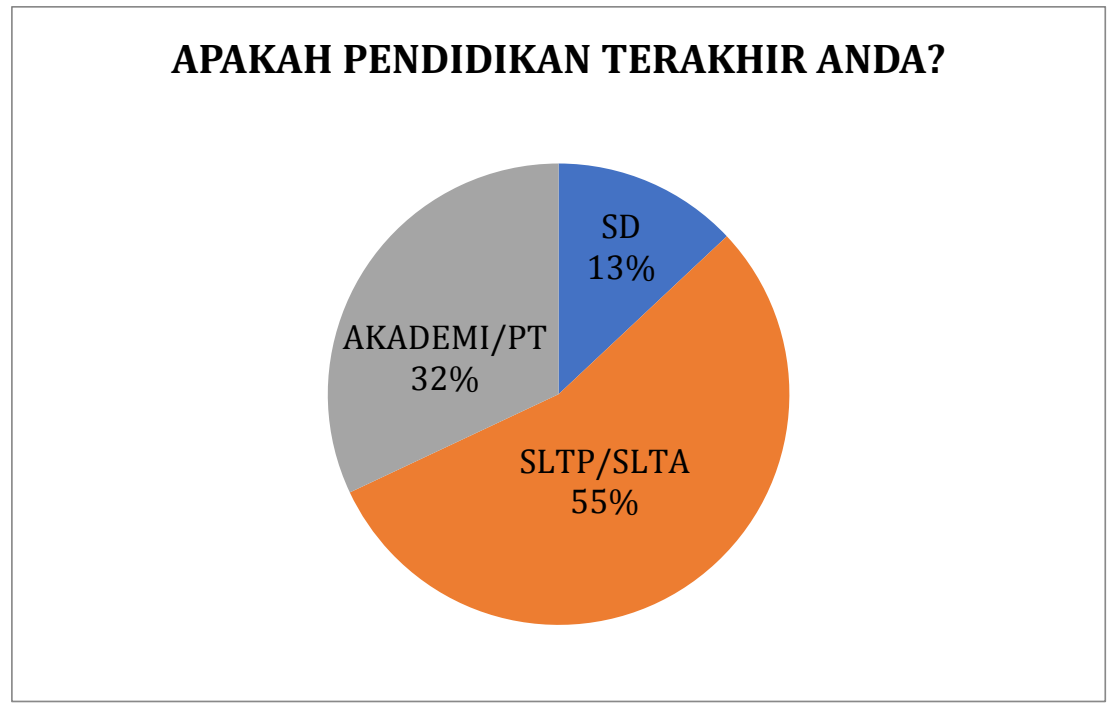

Gambar 18. Tingkat pendidikan responden 
Berdasarkan status pekerjaan seperti pada gambar 19, diperoleh responden terdiri dari $65 \%$ status bekerja dan 35\% tidak bekerja. Oleh karena itu dengan besarnya persentase tingkat bekerja diharapkan memiliki kemampuan untuk memiliki modal untuk membeli perangkat alat dan bahan dalam mengaplikasikan fischerdi lingkungan rumahnya.

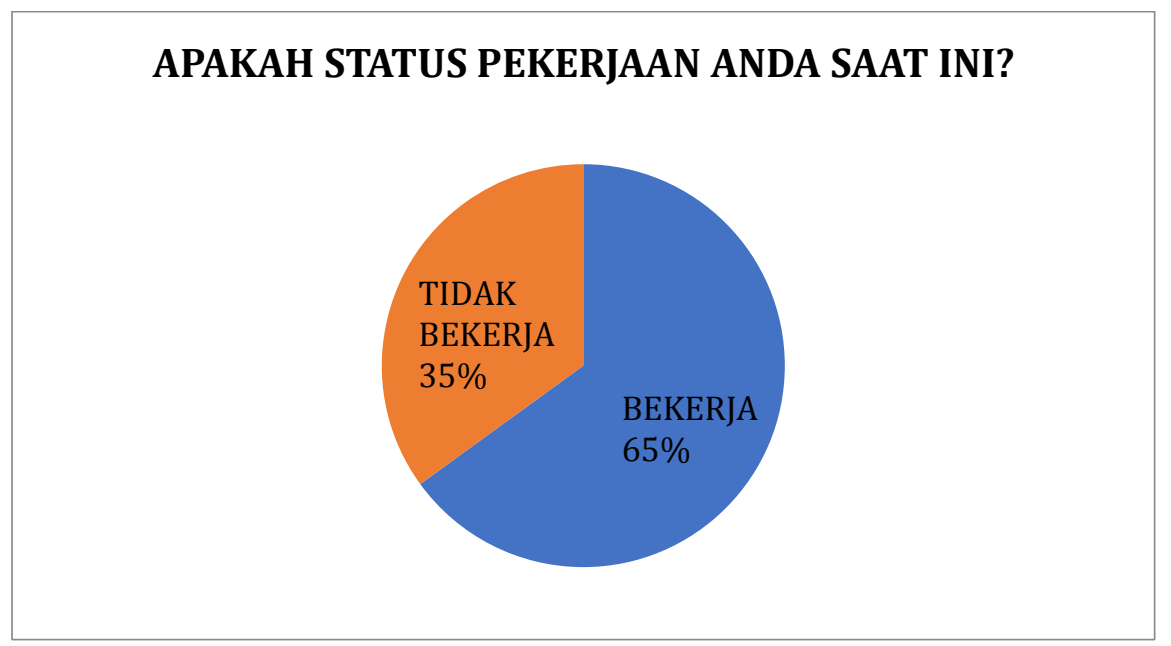

Gambar 19. Status pekerjaan responden

\subsection{Pemahaman Peserta terhadap Sosialisasi Materi dan Praktik Penggunaan Fischer}

Setelah dilakukan ceramah, diskusi dan praktik pemasangan fischer, disebarkan kuesioner yang menanyakan 6 hal dasar mengenai penggunaan fischer kepada peserta. Pertanyaan tersebut mengenai pengetahuan awal tentang fischer, perbedaan fischer, dan paku. Fungsi fischer, alat dan bahan yang digunakan pada pemasangan fischer, penentuan titik pemasangan fischer, dan proses pemasangan fischer. Berdasarkan hal tersebut seperti pada gambar 20, diperoleh hasil yaitu lebih dari 75\% responden memahami materi yang disampaikan dengan baik.

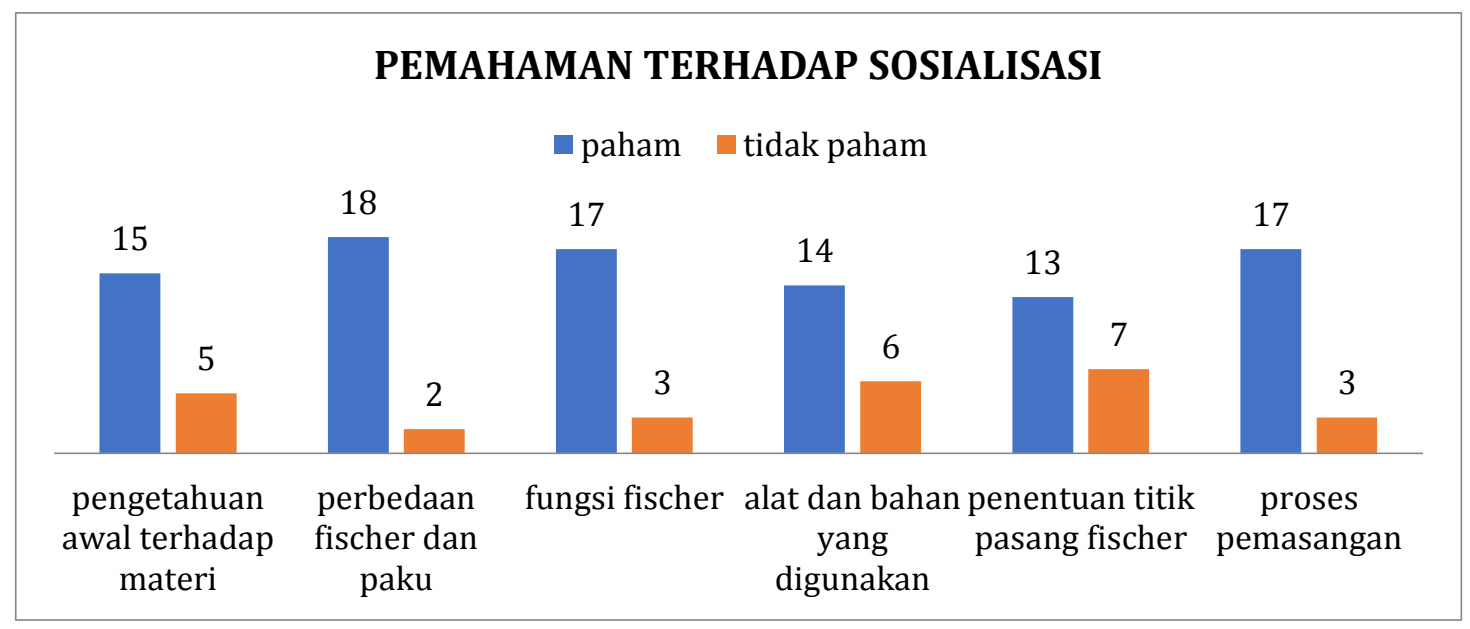

Gambar 20. Grafik pemahaman materi sosialisasi pemasangan fischer

\section{KESIMPULAN}

Adapun kesimpulan dari kegiatan sosialisasi ini antara lain:

1. Pemasangan fischer untuk merapikan benda di rumah telah memberikan tambahan wawasan pengetahuan bagi peserta mitra di Kecamatan Sematang Borang dalam mewujudkan rumah yang rapi. 
2. Peserta secara keseluruhan berperan aktif dalam mengikuti kegiatan sosialisasi mulai dari pendistribusian dan pemaparan materi, diskusi, praktik pemasangan fischer, dan pengisian kuesioner. Berdasarkan data kuesioner diperoleh bahwa lebih dari 75\% peserta telah cukup memahami tentang manfaat dan pengaplikasian fischer dalam penataan benda di lingkungan rumahnya.

\section{DAFTAR PUSTAKA}

Builder Indonesia. (2018). Indonesia.: Inovasi Dunia Konstruksi dan Bangunan Terkini. Cara Memasang Fischer Atau Angkur Dinding di Tembok. Retrieved Mei 13, 2020, from https://www.builder.id/cara-memasang-fischer-atau-angkur-dinding-di-tembok/.

Chressetianto, A. (2013). Pengaruh aksesoris dan elemen pembentuk ruang terhadap suasana dan karakter interior lobi Hotel Artotel Surabaya. Jurnal Intra, 1(1), 1-7.

Darmono. (2006). Teknologi pembuatan bahan bangunan berbahan pasir hasil erupsi merapi dilereng bagian utara. Teknik Sipil, 1(4), 75-89.

Desintha, S. (2019). Persepsi visual terhadap dekorasi fotografi makanan di Imah Babaturan Bandung. Waca Cipta Ruang: Jurnal Ilmiah Desain Interior, 5(2), 388-392. https://doi.org/10.34010/wcr.v5i2.2287

Desriyeni, Rahmah, E., \& Marlini. (2018). Pengelolaan perpustakaan sekolah SMAN 1 Bukit Sundi dan SMAN 1 Lembang Jaya Kabupaten Solok. Jurnal Dinamisia, 2(1), 14-21. https://doi.org/10.1017/CB09781107415324.004

Mastuti, L. N. (2019). Potensi tanah liat gunung merak dalam pengembangan dekorasi engobe dan finishing glasir keramik pagerjurang. Ars: Jurnal Seni Rupa Dan Desain, 22(2), 107-112. https://doi.org/10.24821/ars.v22i2.2532

Mujiraharjo, F. N., \& Basuki, M. (2019). Analisis indeks kepuasaan masyarakat terhadap pelayanan publik bidang kesehatan (studi kasus: faskes tingkat I Mojokerto). Jurnal Desiminasi Teknologi, 7(2), 93-98.

Rahmah, E., Emidar, \& Zulfikarni. (2018). Pengembangan perpustakaan sekolah berbasis teknologi informasi di SMA Negeri 2 dan SMA Negeri 3 Padang. Jurnal Dinamisia, 2(1), 6-13.

Rusli. (2011). Upaya peningkatan hunian kampung nelayan di Kota Donggala studi kasus Kelurahan Labuan Bajo dan Kelurahan Boneoge. Jurnal Ruang, 3(1), 39-44.

Tjandra, H. C., Ardana, I., \& Yong, S. De. (2017). Perancangan ulang interior rumah tinggal Solo Baru dengan pendekatan smart \& eco design (studi kasus luasan 100, 150 \& 240). Jurnal Intra, 5(2), 919-928.

Veronica, G. (2018). Implementation of embroidery techniques in interior decoration elements at kedai teh sinau, Yogyakarta. Jurnal Ilmiah Desain \& Konstruksi, 17(2), 104-114.

Werdiningsih, H., Indrosaptono, D., \& Darmawan, E. (2015). Perubahan tata letak ruang rumah tinggal di sepanjang jalan utama lingkungan dikaitkan dengan kegiatan ekonomi. Jurnal Modul, 15(2), 107-123. https://doi.org/10.1017/CB09781107415324.004 